\title{
REGISTRANDO PARA O FUTURO: FOTOGRAFIA E PATRIMÔNIO HISTÓRICO-DOCUMENTAL DE SÃO GABRIEL
}

\author{
Registering for the future: photography and historical- \\ documentary patrimony of São Gabriel
}

\section{Melina Pereira}

Arquivista e Técnico de Arquivo - Prefeitura Municipal de São Gabriel, RS, Brasil.

\section{Glaucia Vieira Ramos Konrad}

Prof ${ }^{a}$ Dra . Universidade Federal de Santa Maria, RS, Brasil. Doutorado em História pela Universidade Estadual de Campinas (UNICAMP-SP).

\section{Resumo}

Esta pesquisa apresenta o registro fotográfico das edificações de São Gabriel. Os registros utilizados compreendem as décadas de 1920 a 1941. Como podemos demonstrar através dos arquivos fotográficos a desvalorização do patrimônio histórico cultural e arquitetônico de São Gabriel? Demostrará através dos registros fotográficos: identificando cada edificação com fotografias do ano de 1920 a 1941 e contando a história de cada edificação, comparando o antes e o depois. A pesquisa foi realizada por meio de estudo e análise do Registro Fotográfico das edificações entre o ano de 1920 a 1941 , demonstrando a importância da fotografia como documento arquivístico. As etapas desenvolvidas foram: a elaboração do referencial teórico, o registro fotográfico foi realizado em um arquivo pessoal e a seleção de 23 edificações. A etapa final foi fotografar as edificações entre 2016 e 2017. Conclui-se que o trabalho desenvolvido é de extrema importância para demonstrar a preservação da memória da cidade de São Gabriel e auxiliar futuras pesquisas, na arquitetura, arquivologia e história.

Palavras-chave: Patrimônio Cultural. Fotografia. Edificações.

\begin{abstract}
This research presents the photographic record of the buildings of São Gabriel. The records used comprise the decades from 1920 to 1941. How can we demonstrate through the photographic archives the devaluation of the historical and cultural patrimony of São Gabriel? Will demonstrated through photographic records: identifying each building with photographs from the year 1920 to 1941 and telling the story of each building, comparing the before and after. The research was carried out by means of study and analysis of the Photographic Record of the buildings, demonstrating the importance of photography as an archival document. The stages developed were: the elaboration of the theoretical reference, the photographic record was carried out in a personal archive and the selection of 23 buildings. The final step was to photograph the buildings between 2016 and 2017. It is concluded that the work developed is of extreme importance to demonstrate the preservation of the memory of the city of São Gabriel and to assist future research in architecture, archivology and history.
\end{abstract}

Keywords: Cultural Heritage. Photography. Buildings

\section{Sumário}

1. Introdução; 2. Metodologia; 3. Resultados e discussões; 3.1 Patrimônio Cultural; 3.2 Patrimônio Arquivístico Documental; 3.3 Fotografia; 3.4 Breve História de São Gabriel; 3.5 Edificações; 3.6 Igreja do Galo; 3.7 Loja Maçônica Rocha Negra $n^{\circ}$ 1; 3.8 Prefeitura Municipal; 3.9 Sobrado da Praça; 3.10 Cine Teatro Harmonia; 4. Conclusão; Referências 


\section{INTRODUÇÃO}

Este trabalho visa apresentar o registro fotográfico das edificações de São Gabriel. Os registros fotográficos utilizados nesta pesquisa compreendem as décadas de 1920 a 1941 , as edificações foram construídas no período de 1800 a 1940. Com o objetivo de identificar cada edificação, contar a história de cada uma, perceber as modificações e a preservação das edificações.

A possibilidade de poder mostrar a consolidação do patrimônio cultural e histórico de São Gabriel, sua trajetória através do registro fotográfico, será extremamente encantador e de grande valia para que sua memória não se perca. Parafraseando Rieth (2007, p. 26), "descrevo o histórico de São Gabriel com seus casarões, que trouxeram a beleza e a nobreza à "Terra dos Marechais" [...]". Este trabalho segue este sentimento de valorização deste patrimônio a partir do documento fotográfico.

Cidade de origem hispano portuguesa São Gabriel, conhecida como Terra dos Marechais. Lugar onde viveram o Coronel José Plácido de Castro, líder da revolução acriana, de Alcides Maia primeiro gaúcho a ingressar na Academia Brasileira de Letras $(A B L)$ e cidade onde nasceu o presidente Hermes da Fonseca. Lá também foi onde morreu o índio missioneiro Sepé Tiarajú, que lutou contra Portugueses e Espanhóis. Aliar o estudo da arquivologia, ciência que trata os documentos, não importando seu suporte, com o fascínio da fotografia, neste sentido, a fotografia/documento se revela num poderoso instrumento de reativar a memória e de conscientização para a preservação.

\section{METODOLOGIA}

Este trabalho foi realizado por meio de estudo e análise do Registro Fotográfico das edificações de São Gabriel entre o ano de 1800 a 1940, demonstrando a importância da fotografia como documento arquivístico. As etapas desenvolvidas foram: a elaboração do referencial teórico, a pesquisa do registro fotográfico foi realizada no arquivo pessoal de Isaias Evangelho, não se sabe a data especifica das fotografias, as mesmas estão digitalizadas e sem nenhum tratamento arquivístico digital. A etapa final foi a seleção de 23 edificações: estação da estrada de ferro, três escolas, dois clubes, três igrejas, loja Maçônica Rocha Negra, hospital, prefeitura municipal, sobrado da praça, banco, instituto lar das meninas, teatro e sete residências.

As fotografias analisadas mostram o passado das edificações, o tratamento do Patrimônio Cultural de São Gabriel a importância da preservação deste patrimônio. Após a seleção das fotografias o segundo passo foi fotografar as edificações entre 2016 e 2017.

\section{RESULTADOS E DISCUSSÕES}

\subsection{PATRIMÔNIO CULTURAL}

A Constituição Federal de 1988 define patrimônio cultural e propõe políticas para a sua manutenção e preservação. Neste sentido, no:

Art. 216 Constituem patrimônio cultural brasileiro os bens de natureza material e imaterial, tomados individualmente ou em conjunto, portadores de referência à identidade, à ação, à memória dos diferentes grupos formadores da sociedade 
brasileira nos quais se incluem: I - as formas de expressão; II - os modos de criar, fazer e viver; II - os modos de criar, fazer e viver; III - as criações científicas, artísticas e tecnológicas; IV - as obras, objetos, documentos, edificações e demais espaços destinados às manifestações artístico-culturais; $\mathrm{V}$ - os conjuntos urbanos e sítios de valor histórico, paisagístico, artístico, arqueológico, paleontológico, ecológico e científico. (BRASIL, 1988).

De acordo com Silva (2011, p. 407),

O Patrimônio Histórico Cultural representa uma parcela importante na riqueza de muitas cidades e regiões. É a identidade de um povo nas provas físicas que recordam os atos e feitos de nossos antepassados, embora, por muito tempo esse patrimônio não tenha sido encarado como um bem de natureza econômica, e, portanto, de natureza produtiva, capaz de gerar uma serie de serviços e benefícios para a sociedade.

Concordando com a ideia de Silva de que o patrimônio é uma riqueza de natureza produtiva que gera serviços e benefícios. Na mesma lógica, Horta (1999, p. 9) diz que "nada substitui o objeto real como fonte de informação sobre a rede de relações sociais e o contexto histórico em que foi produzido, utilizado e dotado de significado pela sociedade que o criou." Patrimônio arquitetônico consiste em tudo aquilo que se pode ver e se pode tocar.

\subsection{PATRIMÔNIO ARQUIVÍSTICO DOCUMENTAL}

Os documentos são criados para atender uma demanda não importando seu suporte ou conteúdo, ou seja, estão unidos entre si por sua organicidade, gerando uma informação.

De acordo com o Arquivo Nacional (1995, p. 11),

Documento é toda informação registrada em um suporte material, suscetível de ser utilizada para consulta estudo, prova e pesquisa, pois comprovam fatos, fenômenos, formas de vida e pensamentos do homem numa determinada época ou lugar.

Patrimônio documental arquivístico pode ser qualquer tipo de documento que registra ou documenta algo, o conteúdo informativo ou suporte no qual se consigna, também pode ser considerado um documento, tal como, os casarões de São Gabriel.

Uma definição de patrimônio arquivístico documental que dê conta de responder a relação entre documento fotográfico e o arquitetônico, no caso específico dos casarões de São Gabriel, encontraram em Lage uma resposta para esta questão:

\footnotetext{
Mais do que definir, importa-nos, no entanto, estabelecer o conceito válido de Património Documental numa perspectiva teórica que atravessa domínios do conhecimento tão vastos, consolidados e formalizados como o são as Ciências da Documentação e Informação, a História das Populações e a Demografia Histórica e os Estudos Culturais e Sociais das Ciências e das Técnicas, e na perspectiva prática da sua compreensão necessária à sua salvaguarda, difusão e desenvolvimento. (LAGE, 2002, p. 14).
}

Nesse sentido, o patrimônio arquivístico documental está relacionado ao tratamento dispensado aos documentos, em razão do seu valor histórico, mas também a memória e a preservação destes.

Para Rousseau e Couture,

O patrimônio arquivístico comum é composto pelos arquivos que formam uma parte do patrimônio nacional de um ou de vários estados, que não podem ser divididos sob pena de perderem o seu valor administrativo, legal ou histórico. (ROUSSEU E COUTURE, 1998, p. 113). 
Rousseau e Couture destacam que os arquivos não podem ser divididos, porque é uma parte do patrimônio, se forem divididos perdem o seu valor, conforme o Princípio da Organicidade os documentos tem que ter uma relação entre si.

\subsection{FOTOGRAFIA}

Como forma de memória a fotografia traz a preservação da sua essência intrínseca do significado do passado e mostrando a mudança ao longo do tempo. A fotografia nada mais é que a luz esculpida, dando forma a algo que queremos guardar para sempre.

A relação entre a noção de tempo, lugar e memória também é destacada por Dubois.

De acordo com Dubois,

É evidente que num primeiro tempo a fotografia pode intervir em tais práticas como simples meio de arquivagem, de suporte de registro documentário do trabalho do artista in situ, ainda mais porque esse trabalho se efetua na maioria das vezes num lugar (e às vezes num tempo) único, isolado, cortado de tudo e mais ou menos inacessível, em suma, um local e um trabalho que, sem a fotografia, permaneciam quase desconhecidos, letra morta para todo o público. (DUBOIS, 1993, p. 283).

Dubois evidência que a fotografia é um trabalho único. A fotografia certamente é um tempo único que faz com que as lembranças sejam retomadas e guardas, com um passado em comum.

O patrimônio documental está inserido num campo denso e complexo de conhecimentos multidisciplinares, que trata tanto de conhecimentos específicos (arquivologia/fotografia) quanto amplos (História e Arquitetura), mas todos ligados à memória e preservação do patrimônio cultural.

\subsection{BREVE HISTÓRIA DE SÃO GABRIEL}

A História da cidade de São Gabriel teve início com os conflitos entre portugueses e espanhóis, a partir do Tratado de Tordesilhas que repartiu esses dois países, mais tarde foram definidas as fronteiras com os Tratados de Madri e Santo Ildefonso. Assinado o Tratado de Madri que entregaria os Setes Povos das Missões a Portugal em troca receberia a Colônia de Sacramento.

Em $1^{\circ}$ de outubro de 1777 foi firmado o Tratado de Santo Ildefonso, uma linha demarcatória foi seguida, que recuou bastante para o interior do Rio Grande do Sul. O Tratado de Santo Ildefonso mencionava um dos pontos que era divisor das águas o Cerro do Batovi em São Gabriel.

Segundo Myskiw (2015, p. 55), "a assinatura do Tratado de Santo Idelfonso, em outubro de 1777, por sua vez, pôs fim aos conflitos entre castelhanos e portugueses na porção meridional da América do Sul."

Fundada pelo espanhol Dom Félix de Azara que era naturalista, matemático, historiador e antropólogo, em 02 de novembro de 1800 estabeleceu a primeira povoação denominada Vila do Batovi, que tinha como padroeiro o Arcanjo São Gabriel, no mesmo dia foi feita a planta da Vila, a primeira construção a ser levantada foi a igreja. 
Dom Félix de Azara correspondia-se com Miguel Lastaria, que era secretário do Vice-Rei Marquês de Avilez. Ao todo foram trinta e seis cartas trocadas, mas somente sete conhecidas. As setes cartas que foram transcritas por Figueiredo e na primeira carta constava o sofrimento de Dom Felix com a situação do povoado. Dizia a carta de 12 de dezembro de 1800:

Não há dúvida que Deus dirige estas cousas, pois vemos que tem prosperado, mais do que se podia pensar, num desterro como este centro de todas iniquidades. Sofro sem embargo e tudo ofereço a Deus por meus pecados e sofrerei se assim merecer até quando deixar a pele. (FIGUEIREDO, 1984, p. 68).

Em 1801 Dom Félix de Azara parte da Vila do Batovi para regressar à Corte. Após ser incendiada a Vila do Batovi foi deslocada para uma região chamada "Entre Rios".

O segundo povoado teve o nome de São Gabriel, que se formou ao nordeste do Cerro do Batovi, não muito longe da primeira povoação. Em 1817 São Gabriel do Batovi é transferida para a margem esquerda do Vacacaí surge então a atual São Gabriel.

O renomado romancista francês Alexandre Dumas, ao escrever as memórias de seu amigo Giuseppe Garibaldi, relata que este passou rapidamente por São Gabriel antes de ir para Montevidéu no Uruguai, e fez um grande amigo Anzani um oficial italiano exilado revolucionário que lutou na França.

Dumas enfatiza,

\begin{abstract}
Aproximando-me de São Gabriel, por ocasião da retirada que não fazia muito tempo efetuáramos, eu ouvira falar de um oficial italiano dotado de um grande caráter, de uma grande bondade e instrução, que, exilado como arbonaro, lutara na França no 5 de junho de 1832, depois no Porto, em Portugal, durante o longo cerco que valera ‘aquela cidade o título de "inexpugnável", e que enfim, forçado como eu a deixar a Europa, viera empregar sua coragem e seu saber a serviço das jovens repúblicas sul-americanas. Os atos de coragem, de sangue-frio e de força que se Ihe atribuíam haviam-me feito dizer e repetir: "Ao encontrar este homem, ele será meu amigo". Este homem chamava- se Anzani. (DUMAS, 1999, p. 144).
\end{abstract}

Somente em 15 de dezembro de 1859 São Gabriel foi elevada como cidade, pela lei $n^{\circ} 433$.

\title{
3.5 EDIFICAÇÕES
}

Em 1922 na obra de Costa em O Rio Grande do Sul (Completo estudo sobre o estado) apresenta o estudo demográfico sobre os prédios da cidade de São Gabriel do ano de 1886 até o ano de 1921.

De acordo com Costa (1922, p. 389),

Em 1886 a cidade de São Gabriel contava 496 prédios; em 1897, 597; em 1900, 695; em 1912, 865; em 1913, 961; em 1917, 1.236; em 1918, 1.344; em 1921, 1.360 prédios, verificando-se nos últimos anos, um aumento extraordinário na edificação urbana, principalmente nas construções, erguendo-se belos edifícios.

Em 1922, o autor salientava o aumento das edificações e elogiava as mesmas. A apresentação das edificações foi desenvolvida por temas, mostrando um pouco da história de cada edificação, a data de construção e as edificações tombadas. 


\subsection{IGREJA DO GALO}

Em 1817 conhecida como Igreja do Galo (Igreja Nossa Senhora do Rosário Bom Fim) foi o primeiro templo de alvenaria levantado em São Gabriel, sua torre tinha um galo de bronze, que em 1985 foi roubado.

Segundo Figueiredo (1984, p. 240),

Quanto ao significado dos galos nas torres das Igrejas, é muito vaga a sua definição. Parece ser de origem palestinense, que tinha no galo o anunciador da chuva e do sair do sol. Lembra a fraqueza de São Pedro. (Mt. 26-34). É a trombeta da consciência a respeito do mal feito. É o anunciador. Afugenta os demônios. Uma Velha tradição da nossa campanha diz que os espíritos do mal se retiram das trevas da noite ao primeiro cantar do galo.

O autor explica que o galo é uma espécie de amuleto que afugenta tudo de ruim. $\mathrm{O}$ galo de bronze foi trazido pelo Marechal João de Deus Menna Barreto.

Figura 1 - Igreja Nossa Senhora do Rosário Bom Fim

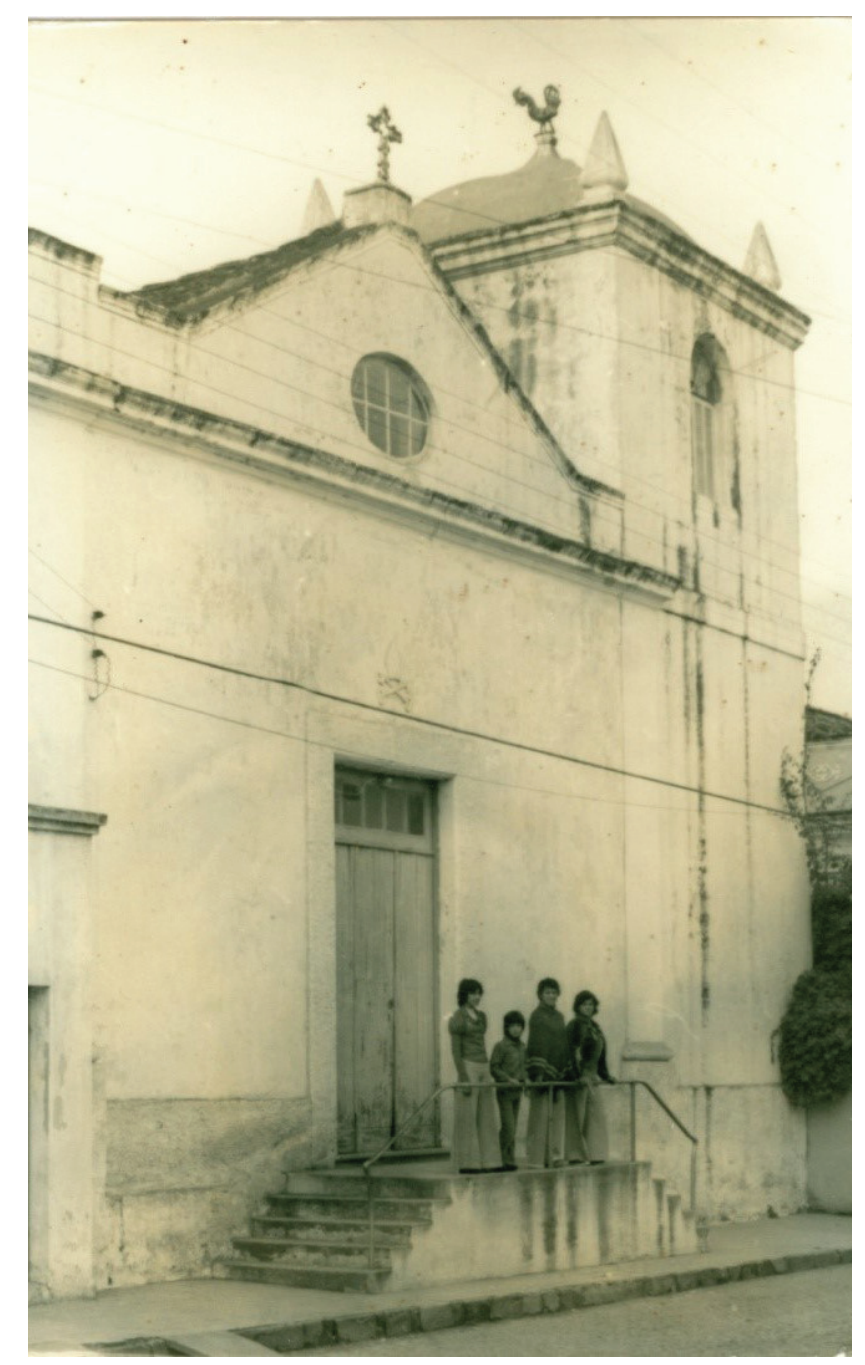

Fonte: Isaias Evangelho

A Igreja Nossa Senhora do Rosário Bom Fim em 1994 foi tombada pelo IPHAE (Instituto do Patrimônio Histórico e Artístico do Estado) restaurada em 2011 e hoje é o seu Municipal Nossa Senhora do Rosário Bom Fim, que é aberta ao público com várias exposições como: Lanceiros Negros, Artes Visuais, Fotografias e Fósseis. 
O galo roubado acabou sendo substituído por outro galo, não obteve nenhuma alteração na fachada do Museu Nossa Senhora do Rosário Bom Fim foi apenas colocada uma grade de ferro e a identificação.

Figura 2 - Museu Municipal Nossa Senhora do Rosário Bom Fim

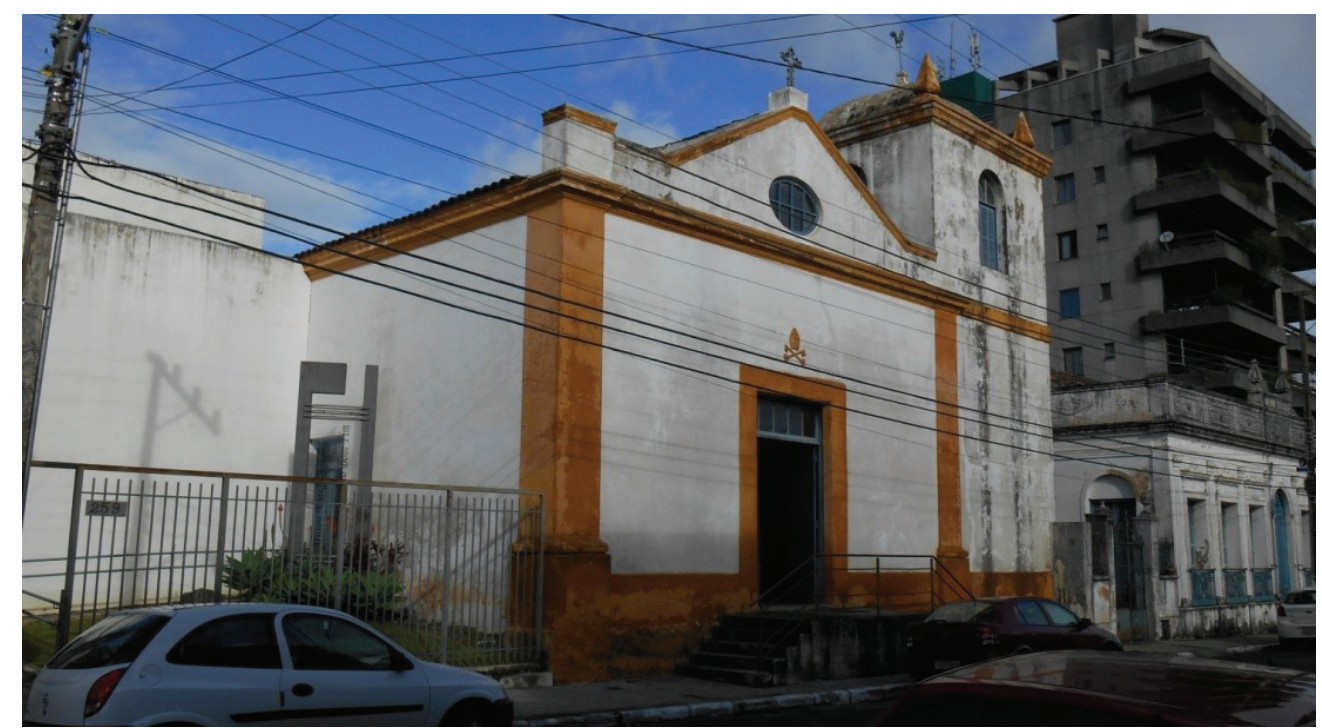

Fonte: Melina Pereira

\subsection{LOJA MAÇÔNICA ROCHA NEGRA Nº 1}

Fundada no ano de 1873, por um grupo de onze maçons liderado pelo Dr. Jonathas Abbott o primeiro Venerável, nos princípios de "Liberdade, Igualdade e Fraternidade". Um fato histórico marcante da Rocha Negra foi à luta em prol da extinção da escravidão, no ano de 1884 foram expedidas aproximadamente 900 cartas de alforria.

Figura 3 - Loja Maçônica Rocha Negra

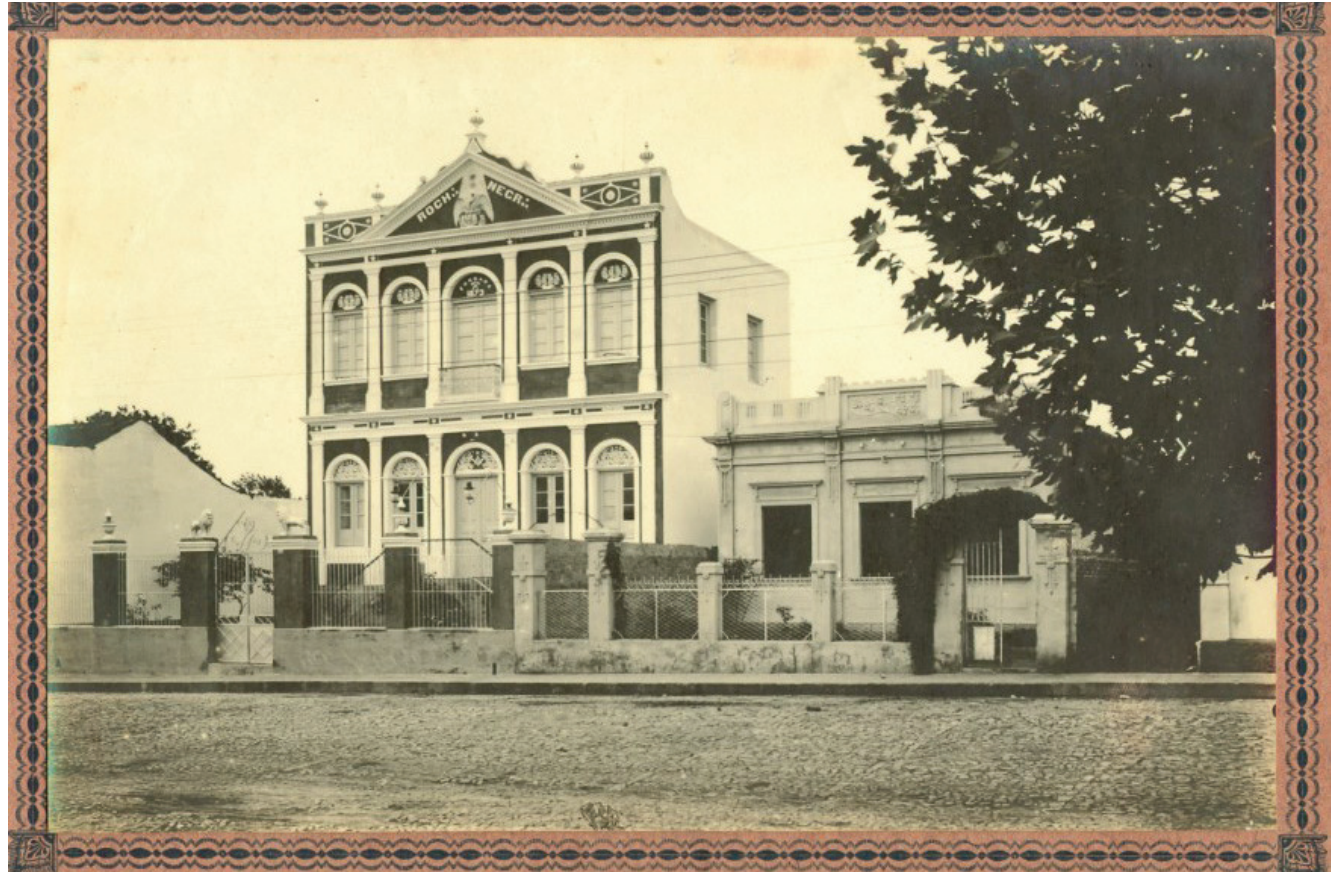

Fonte: Isaias Evangelho

Loja Maçônica Rocha Negra nos dias atuais, não recebeu nenhuma alteração. 
Figura 4 - Loja Maçônica Rocha Negra- 2017

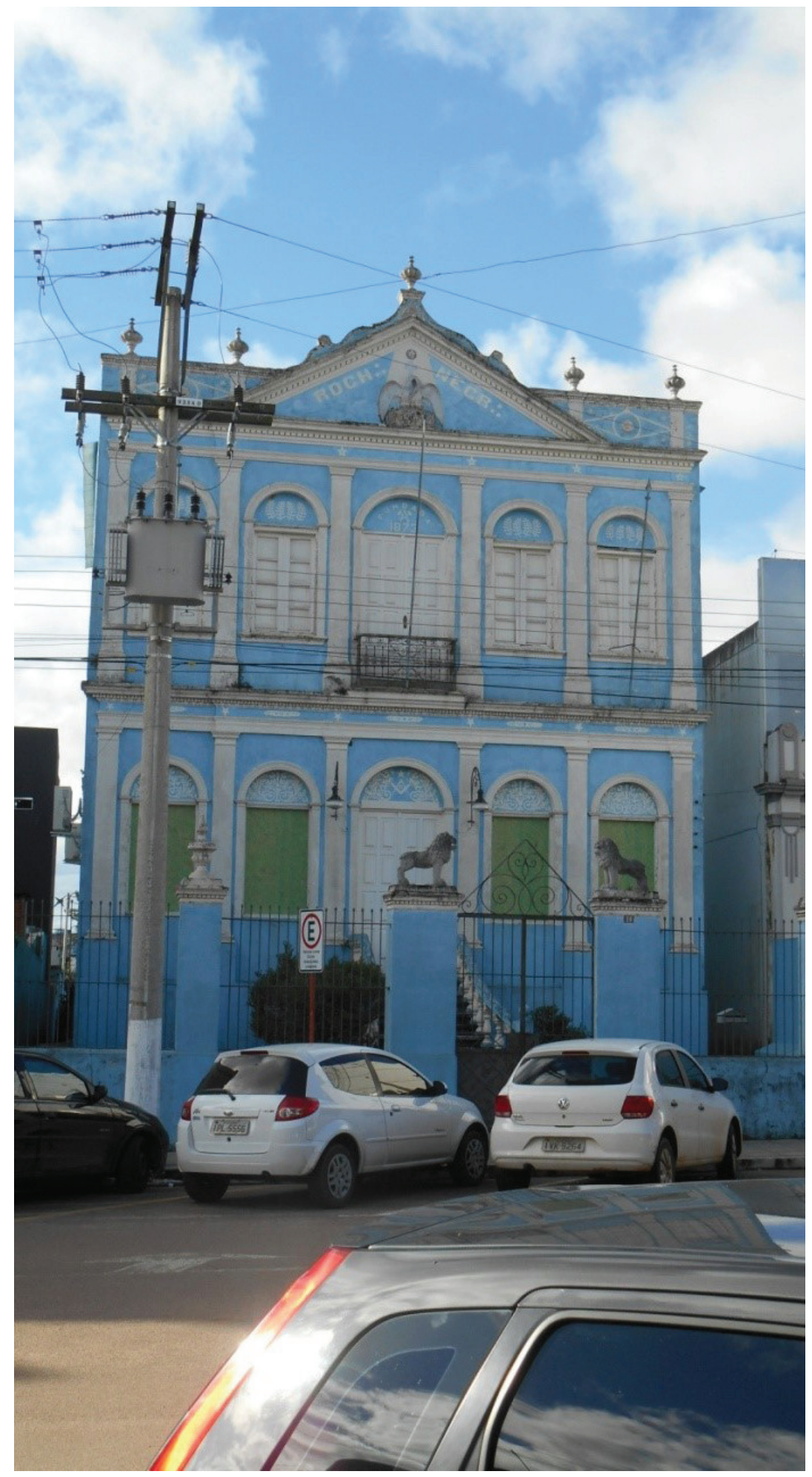

Fonte: Melina Pereira

\subsection{PREFEITURA MUNICIPAL}

A Prefeitura Municipal começou a ser construída em 1918 recebendo o nome de Palácio Plácido de Castro (em homenagem ao desbravador do Acre) a planta da obra era a cópia fiel do "Capitólio" norte-americano. Em 1924 foi concluída a obra sendo inaugurada no mesmo ano. 


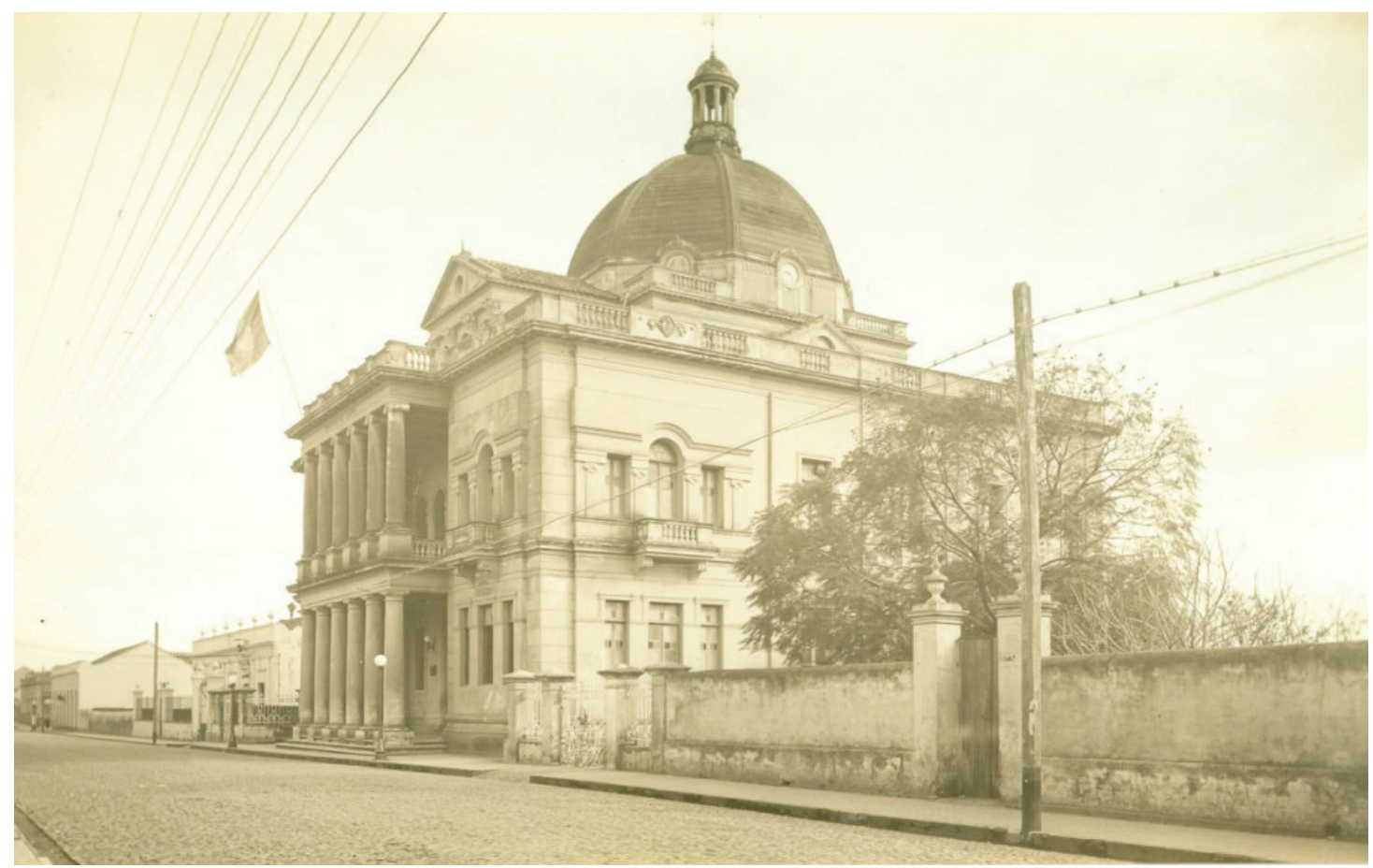

Fonte: Isaias Evangelho

A Prefeitura Municipal fica localizada no centro da cidade obteve uma alteração que foi no muro sendo trocado pelas grades.

Figura 6 - Prefeitura Municipal - 2017

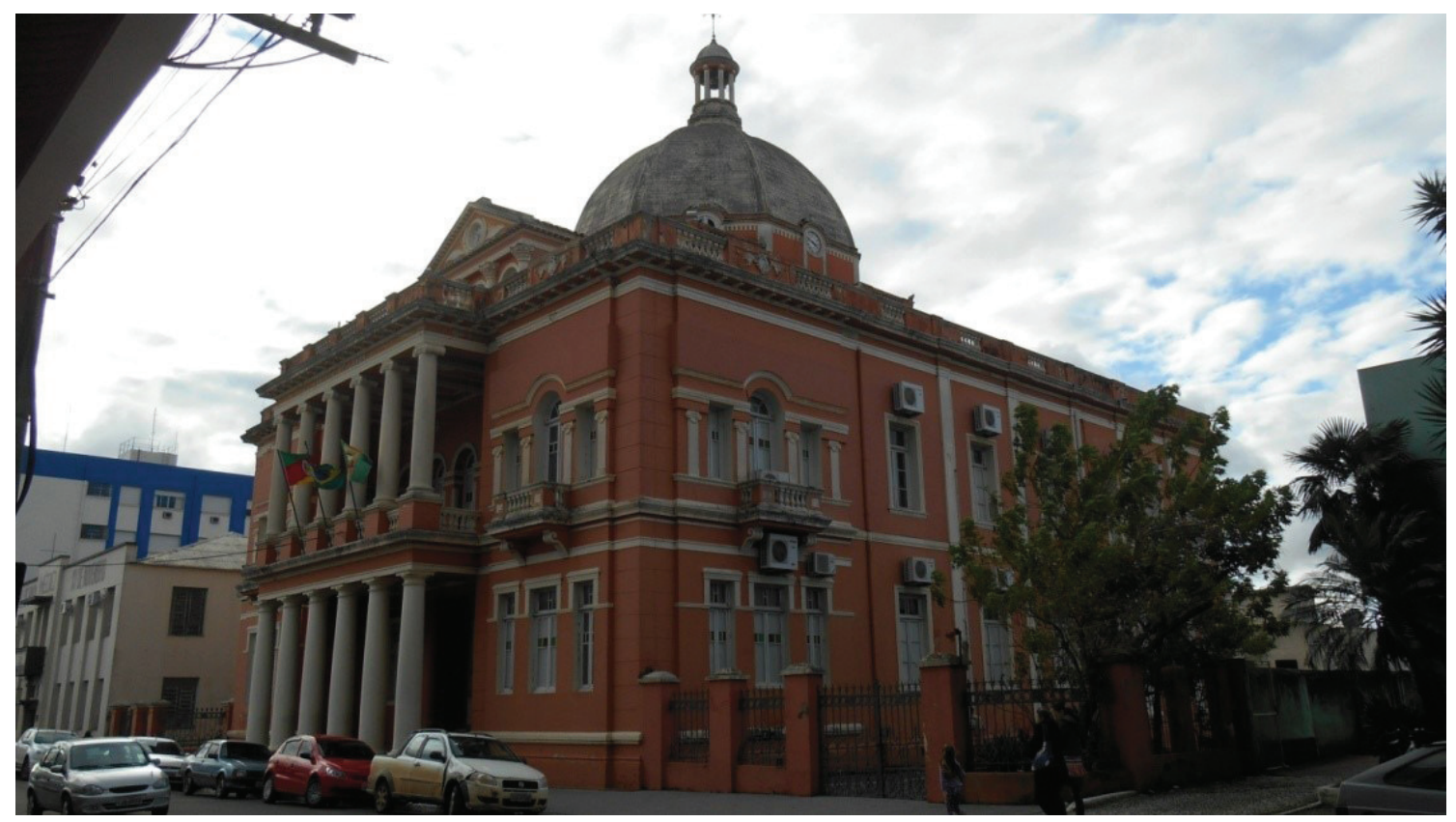

Fonte: Melina Pereira

\subsection{SOBRADO DA PRAÇA}

Construído no ano de 1826 pelo português Francisco José de Carvalho era uma edificação particular, em 24 de setembro de 1974 foi tombado pelo Instituto do Patrimônio Histórico e Artístico Nacional. O Sobrado possui algumas histórias orais entre elas é a que o 
Imperador Dom Pedro II se hospedou lá em 13 de janeiro de 1846.

Figura 7 - Sobrado da Praça

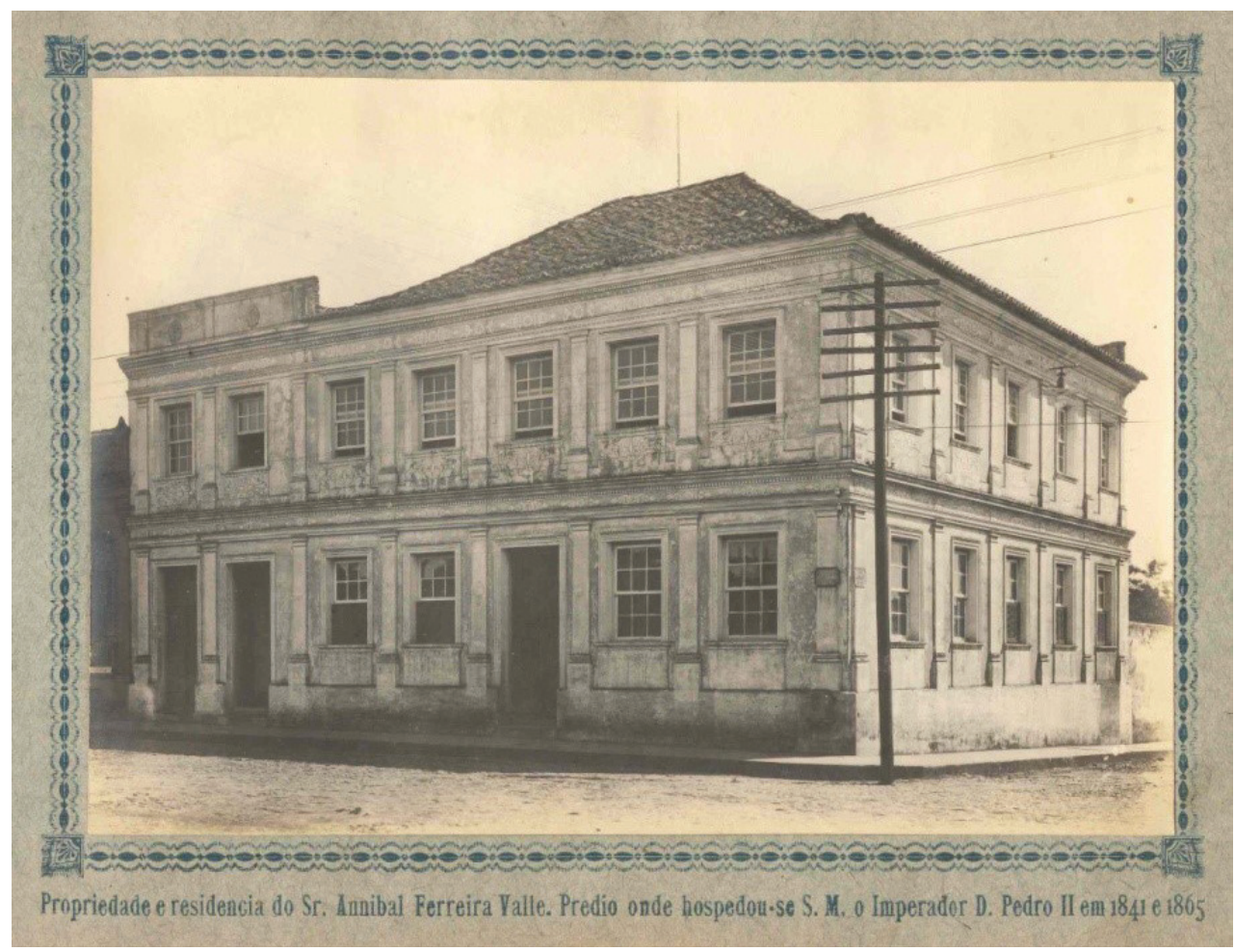

Fonte: Isaias Evangelho

Hoje o prédio é o Centro de Cultura Sobrado da Praça que abriga a Biblioteca Pública Municipal, o Conservatório Municipal e a Secretaria Municipal de Turismo. No Centro de Cultura ocorrem palestras, recitais e exposições fotográficas. O Sobrado fica localizado em frente à Praça Dr. Fernando Abbott, no centro da cidade.

Figura 8 - Centro de Cultura Sobrado da Praça

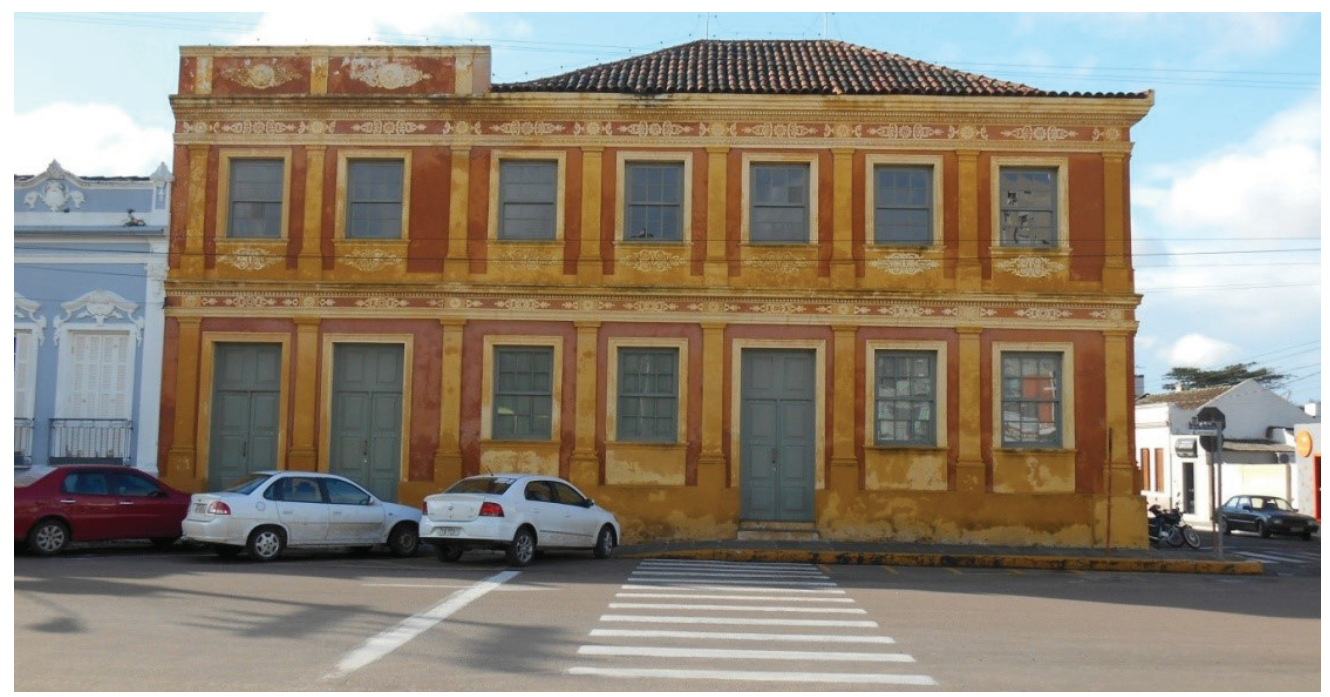

Fonte: Melina Pereira

\subsection{CINE TEATRO HARMONIA}

O prédio foi fundado em 1874, no início chamava-se Sociedade Harmonia Gabrielense. Somente em 1929 passou a se chamar Cine Teatro Harmonia, quando passou por uma 
remodelação. O Cine Teatro Harmonia tinha 56 camarotes para 92 pessoas e plateia de 408 lugares, havia três portas onde o público era selecionado para entrar no prédio com os preços diferenciados.

Figura 9 - Cine Theatro Harmonia

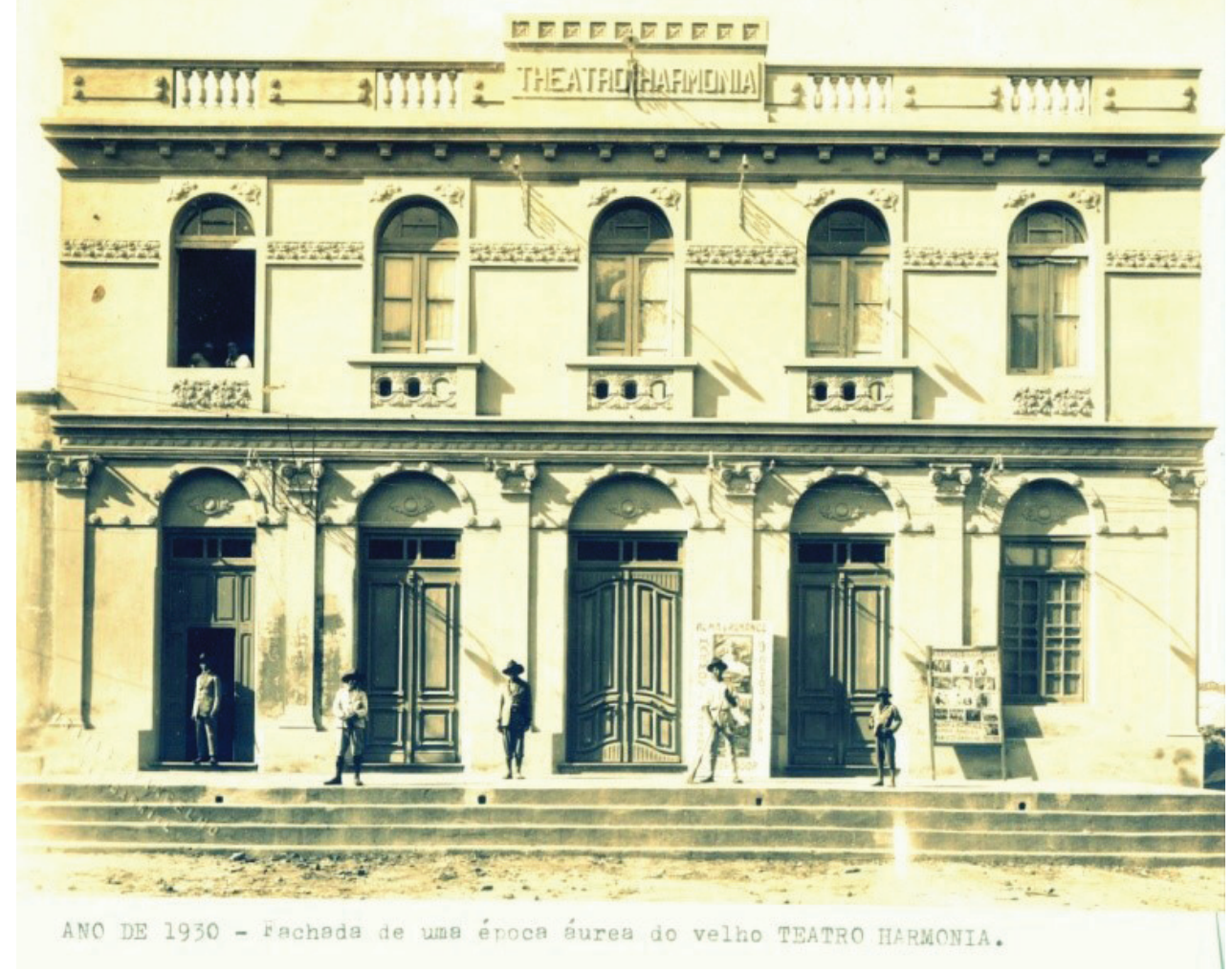

Fonte: Isaias Evangelho

Em 2007 o Theatro Harmonia foi comprado pela Prefeitura Municipal, atualmente o prédio está na primeira etapa de restauração pelo projeto Pró-Cultura RS, Lei nº 13.490/10 é uma lei de incentivo a cultura que antecipa a compensação de recursos destinados ao pagamento do ICMS, por parte das empresas que financiam projetos culturais.

Figura 10 - Theatro Harmonia -restauração/2017

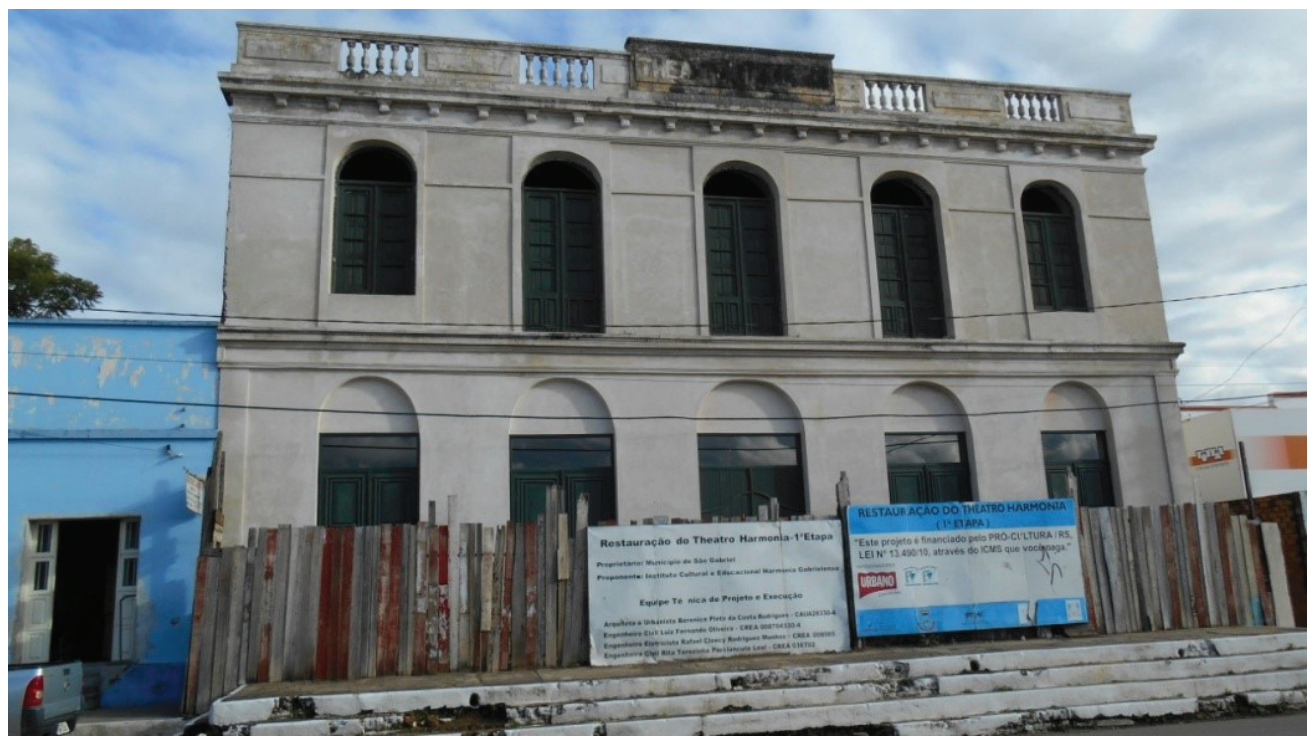

Fonte: Melina Pereira 


\section{CONCLUSÃO}

O Patrimônio Cultural e Histórico da cidade de São Gabriel apresenta diversas edificações com histórias e arquitetura bem diversificadas, essas edificações foram apresentadas a partir do ano de 1800 a 1940 através dos registros fotográficos do ano de 1921 a 1941 , demonstrando a fotografia como documento arquivístico. A fotografia como documento arquivístico nada mais é que a fonte da preservação como forma de memória que mostra o que ocorreu no passado.

As fotografias quando foram selecionadas, já estavam digitalizadas e sem tratamento arquivístico digital. Finaliza-se em mostrar o antes e o depois das casas, contando a história de cada casa.

Como resultado das 23 edificações nos dias atuais foi encontrado edificações com algumas alterações e outras como estavam em 1921 a 1941 quando foram registradas. Notou-se através da análise das fotografias a situação das edificações: uma edificação em restauração, duas edificações em reforma, dois clubes com alterações na fachada, uma igreja com alteração, um prédio pelo IPHAN e outro pelo IPHAE, um prédio demolido, uma igreja com alterações na fachada e as outras edificações sem alterações.

Conclui-se que o trabalho desenvolvido é de extrema importância para mostrar a preservação da memória do Patrimônio Histórico Cultural de São Gabriel e também servir para futuras pesquisas na arquitetura, arquivologia e história.

\section{REFERÊNCIAS}

ARQUIVO NACIONAL (Brasil). Gestão de documentos: conceitos e procedimentos básicos. Rio de Janeiro, 1995 (Publicações Técnicas, 47).

BRASIL. Constituição de 1988. Constituição da República Federativa do Brasil. Disponível em: http:// www2.planalto.gov.br/acervo/constituicao-federal. Acesso em: 07 jun. 2016.

COSTA, Alfredo R. da. O Rio Grande do Sul: completo estudo sobre o estado. Porto Alegre: Livraria do Globo, 1922.

DUBOIS, Philippe. O ato fotográfico e outros ensaios. Campinas, SP: Papirus, 1993.

DUMAS, Alexandre. Memórias de Garibaldi. Porto Alegre: L\& PM, 1999.

FIGUEREIDO, Osorio Santana. São Gabriel desde o Princípio. Santa Maria: Pallotti, 1984.

HORTA, Maria de Lurdes Parreiras; GRUNBERG, Evelina; MONTEIRO, Adriane Queiroz. Guia Básico de Educação Patrimonial. Brasília: IPHAN; Museu Imperial, 1999.

IPHAN, Instituto do Patrimônio Histórico e Artístico Nacional. Patrimônio Cultural. Disponível em: http:// portal.iphan.gov.br/pagina/detalhes/218. Acesso em: 08 jun. 2016.

LAGE, Maria Otília P. Abordar o património documental: territórios, práticas e desafios. Guimarães: 
Éden Gráfico, 2002. (Coleção Cadernos NEPS 4).

LOJA ROCHA MAÇÔNICA NEGRA. São Gabriel. RS. Disponível em: http://www.rochanegra.com. br/?pg=principal. Acesso em: 08 abr. 2017.

OLIVEIRA, Guilherme Silva. Acervo Isaias Evangelho. São Gabriel, 2016.

PARNASO ARQUITETURA. Restauração da Igreja Nossa Senhora do Rosário Bom Fim (Igreja do Galo). Disponível em: http://parnasoarquitetura.blogspot.com.br/2017/03/restauracao-igreja-nossasenhora-do.html.

RIETH, Myrta Luza. Casarões - história e arquitetura de São Gabriel. Porto Alegre: Alcance, 2007.

ROSSEAU, Jean-Yves; COUTURE, Carol. Os Fundamentos da Disciplina Arquivística. Lisboa: Dom Quixote, 1998.

SECRETARIA DA CULTURA DO RIO GRANDE DO SUL. Sistema Unificado Pró-Cultura/RS. Disponível em: http://www.cultura.rs.gov.br/v2/home/proculturars/. Acesso em: 03 jun. 2017.

SILVA, Rogério Piva. O patrimônio arquitetônico histórico cultural do Rio Grande- RS: uma investigação sobre o seu valor contingente. Rio Grande 2011. Disponível em: http://guaiaca.ufpel. edu.br/bitstream/123456789/773/3/O\%20patrimonio\%20arquitetonico $\% 20$ historico $\% 20$ cultural\%20 da $\% 20$ cidade $\% 20$ de $\% 20$ Rio $\% 20$ GrandeRS $\% 20 \% 20$ uma $\% 20$ investigacao $\% 20$ sobre $\% 20$ \% 20 seu $\% 20$ valor\%20contingente.pdf. Acesso em: 02 jul. 2016.

Recebido em: 12/06/2019

Aceito em: 09/07/2019 